\title{
Granular Corneal Dystrophy Type 1: About A Family
}

\author{
Aymane RIDALLAH*, A.R. Kougou Ntoutoume, N. Boutimzine, O. Cherkaoui
}

Department A of Ophtalmology, Mohammed V University, CHU Rabat, Maroc, Morrocco

*Corresponding author: Ridallah Aymane

Abstract

Introduction: Groenouw type 1 granular corneal dystrophy is an autosomal dominant disease, with complete penetrance, following a mutation in the chromatin 5q31 transforming growth factor beta induced protein $\mathrm{H} 3$ gene (TGF $\beta$ I) coding for keratoepithelin. It is a rare corneal condition that is clinically manifested by the presence of central-bilateral, symmetrical white-greyish corneal opacities in the form of snowflakes, involving the Bowman's membrane, the anterior, middle and posterior stroma. Often responsible for pain, photophobia, and a gradual decline in visual acuity. We describe the epidemiological, clinical, tomographic, genetic, and therapeutic aspects of this condition in a family of two children from a consanguineous marriage, whose parents are also affected. Patients and methods: We report the case of a family whose father, mother and their two children (a boy and a girl) are all suffering from type 1 granular dystrophy. Parents are linked by third-degree consanguinity. The first patient was a 6-year-old child, with no personal history, who had consulted for bilateral progressive lowering of visual acuity evolving since birth, with photophobia. We performed an interrogation, a biomicroscopic examination with photographs of the anterior segment, a paraclinical assessment including an optical coherence tomography of the anterior segment. Then we conducted a family survey by examining family members, including her father, mother, and sister. Results: The examination of the child found a BCVA at 5/10. The biomicroscopic examination revealed several small, superficial, central, whitish, confluent, snowflake-shaped, bilateral and symmetrical corneal lesions located on Bowman's membrane and sparing the limb, suggestive of granular corneal dystrophy, complicated with an organic amblyopia. Optical coherence tomography of the anterior segment revealed well-defined hyper-reflective deposits at Bowman's membrane, anterior and middle stroma. The orthoptic treatment instituted was considered insufficient, and the child had been programmed for a therapeutic photokeratectomy.Examination of the rest of the family found similar lesions, at variant degrees, with a favorable evolution under optical correction. Conclusion: Type 1 granular corneal dystrophy is a hereditary condition that appears in the first two decades and affects both sexes. It can manifest itself severely in childhood and cause amblyopia, especially in homozygous individuals. The OCT of the anterior segment confirms the diagnosis, helps in the choice of the best therapeutic technique. In moderate cases, optical correction and symptomatic medical treatment may be sufficient. In severe cases, PKT is the technique of choice, and may in the long term, in case of recurrence, be supplemented by transfixing keratoplasty, a more invasive technique that does not guarantee the absence of recurrences.

Keywords: Corneal dystrophy; Groenouw; consanguinity; OCT SA; Therapeutic photokeratectomy.

Copyright @ 2020: This is an open-access article distributed under the terms of the Creative Commons Attribution license which permits unrestricted use, distribution, and reproduction in any medium for non-commercial use (NonCommercial, or CC-BY-NC) provided the original author and source are credited.

\section{INTRODUCTION}

Granular corneal dystrophy type 1, formerly known as "dystrophy of Groenouw type 1 'is an autosomal dominant disease with full penetrance, described for the first time in 1890 by Groenouw [1]. It is a rare condition, manifested by the presence of central, bilateral, and symmetrical grayish-white corneal opacities, in the shape of snowflakes, interesting the Bowman's membrane,and the anterior, middle and posterior stroma (pre-descemetic form). Often responsible for pain, photophobia, and a gradual decline in visual acuity. This pathology is the result of a mutation in the transforming growth factor beta gene, induced by the protein H3 (TGF $3 \mathrm{I}$ ) of chromosome $5 q 31$ which codes for keratoepithelin [2, 3]. The Groenouw's dystrophy type I phenotype is associated with two TGF $\beta$ I mutations: the more common is R555W where Arginine is changed to Tryptophan, but also the R124S [4]. However, the exact molecular mechanism is not fully understood. We propose to describe the epidemiological, clinical, tomographic, genetics and treatment of this condition in a family of two children,issued from a consanguineous marriage, whose parents are also affected. 


\section{Patients and Methods}

We report the case of a family in which the father, mother and two children's (one boy and girl) all have granular dystrophy type 1 . The parents are united by ties of third degree consanguinity. The first patient was a 6-year-old child, the last of a sibling of 2 children, with no personnal history of eye disease, who had consulted for progressive decline in bilateral visual acuity evolving from birth with photophobia. We had carried out an interrogation, a biomicroscopic examination with photographs of the anterior segment, and an optical coherence tomography (OCT) of the anterior segment. Then we conducted a family survey by examining family members, including his father, mother, and sister. The genetic study could not be done.

\section{RESUlts}

\section{Patient 1}

Examination of the child found bilateral visual acuity without correction reduced to $5 / 10$, with no improvement with optical correction. Biomicroscopy revealed several small, superficial corneal lesions, central, whitish in color, confluent, in snowflakes, bilateral and symmetrical, located on Bowman's membrane and sparing the limbus (figure 1). Examination of the anterior chamber, lens, vitreous and fundus did not note any particularity. Furthermore, we did not find any strabismus or nystagmus. Optical coherence tomography (OCT) of the anterior segment revealed well-limited hyperreflective deposits at Bowman's membrane, anterior stroma and medium (figure 2). Overall, the pediatric examination was normal. Faced with the typical clinical and tomographic appearance of the lesions, we retained the diagnosis of granular dystrophy type 1 , complicated by organic amblyopia. The orthoptic treatment instituted was insufficient, and the child had been scheduled for therapeutic photokeratectomy.

\section{Patient 2}

Examination of the 40-year-old father noted a decline in visual acuity that had progressed for more than 25 years old, his visual acuity was at $3 / 10$ in the right eye and $8 / 10$ in the left one, improved with correction to $8 / 10$ in the right eye and $10=10$ in the left eye.He reported superficial eye pain and early photophobia. The biomicroscopic exam revealed a bilateral and symmetrical superficial corneal damage, identical to that found in his son, suggesting the same diagnosis (figure 3,4). The OCT of the anterior segment found hyperreflective lesions mainly involving the Bowman's membrane (Figure 5).

\section{Patient 3}

Examination of the 32-year-old mother found visual acuity of $10 / 10$ without correction and similar superficial lesions. She did not report any notion of decreased visual acuity since childhood, or to wear an optical correction (Figure 6).

\section{Patient 4}

The eldest sister, 11, presented a bilateral decreasing in visual acuity, at 4/10 on the right eye and $6 / 10$ on the left, upgradeable to $8 / 10$ on the right and $10 / 10$ on the left with correction. Slit lamp examination revealed central, superficial, symmetrical and bilateral corneal involvement, less marked, similar to that found in her brother (figure 7).

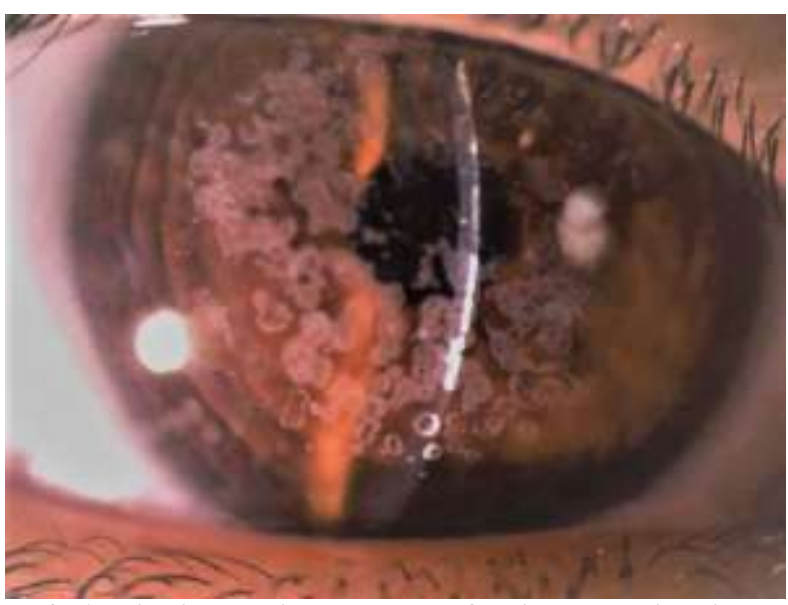

Fig-1: Biomicroscopic appearance of son's dystrophic lesions

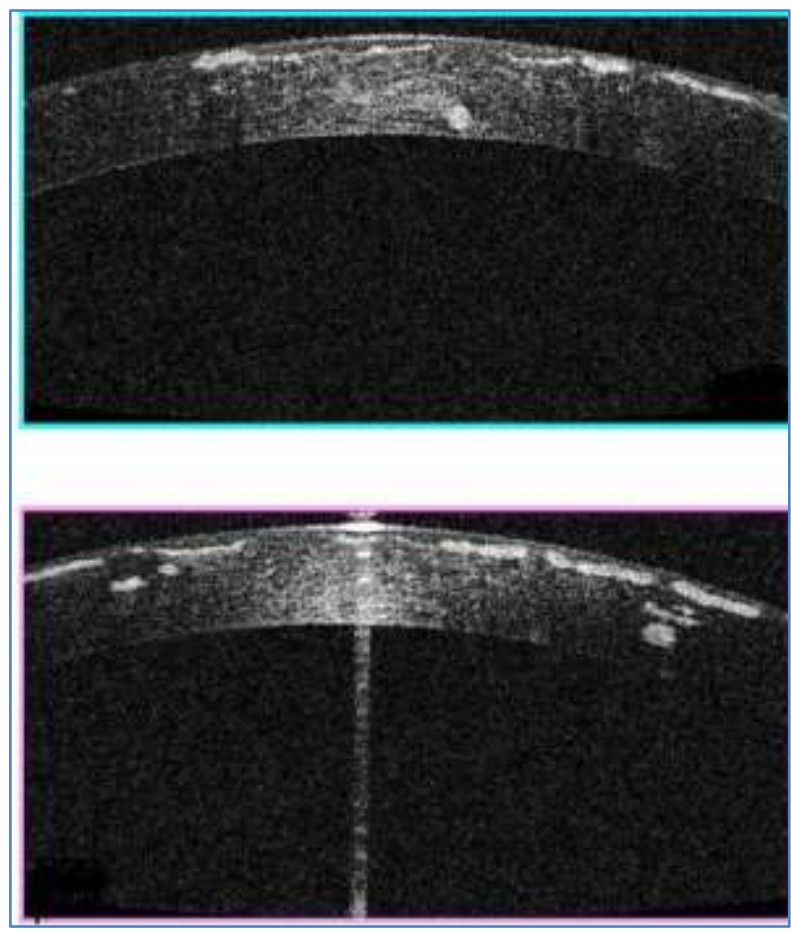

Fig-2: Tomographic appearance of the son's lesions 


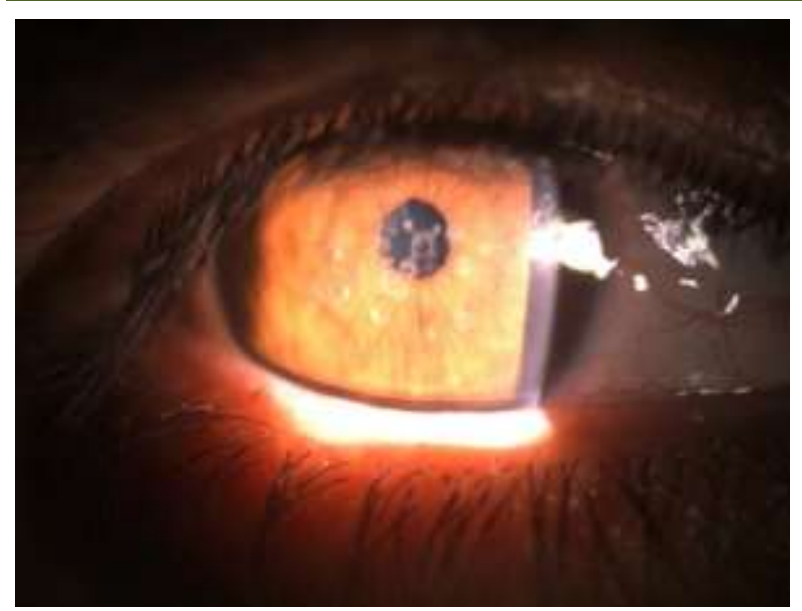

Fig-3: Biomicroscopic appearance of the father's lesions

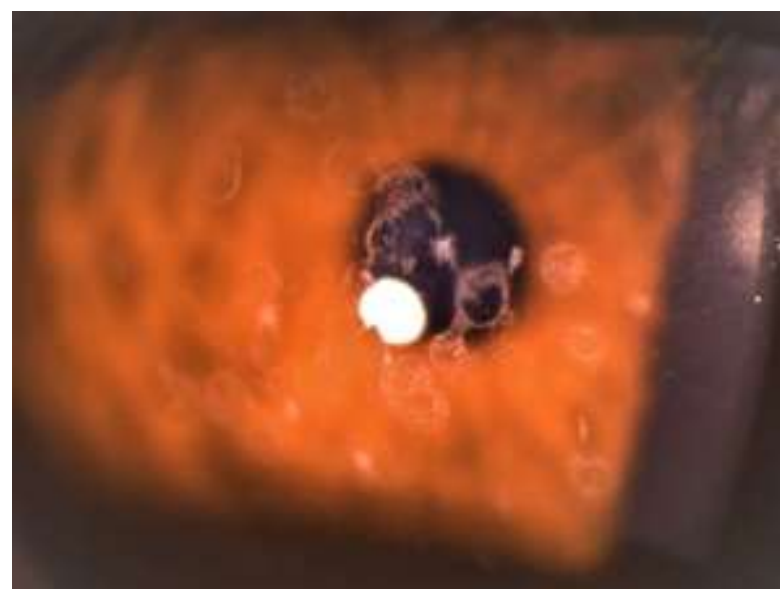

Fig-4: Picture of father's lesions with high magnification
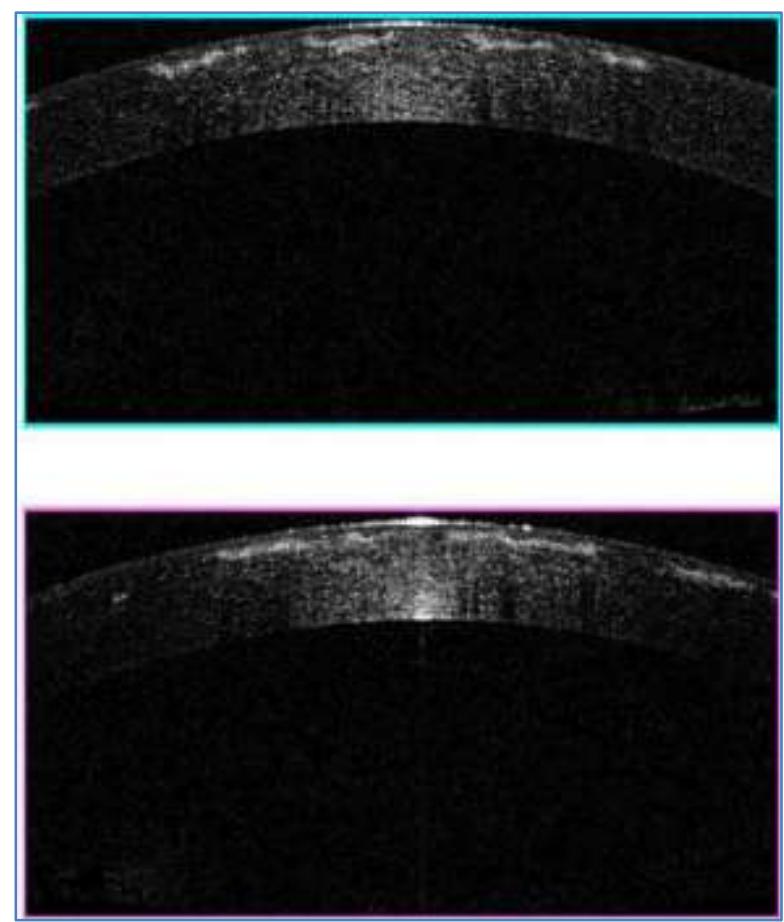

Fig-5: Tomographic appearance of the father's lesions

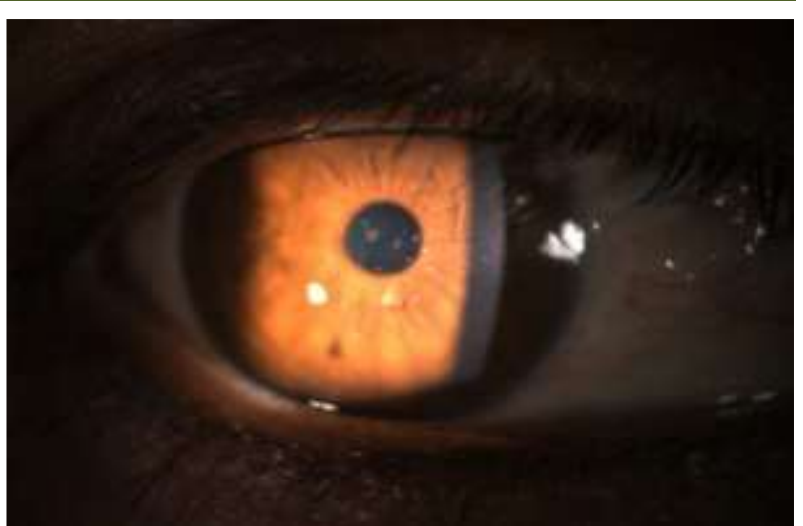

Fig-6: Biomicroscopic appearance of the mother's lesions

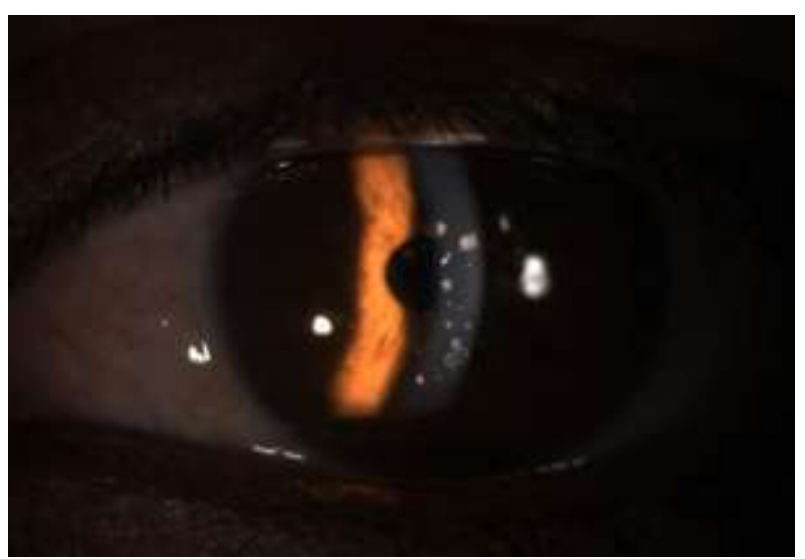

Fig-7: Biomicroscopic appearance of the sister's lesions

\section{DISCUSSION \\ Epidemiological aspects}

The prevalence of granular corneal dystrophy type 1 is not clearly established Intel this day. It is estimated to be around 137 per 1,000,000 people in the USA [5]. This is one of the most common dystrophies linked to the TGF $\beta I$ gene [6]. In our observation, we found inbreeding. This is a rare situation, which may increase the risk of autosomal dominant disease transmission by up to $75 \%$ according to Mendel's laws. In 1890, Groenouw described granular dystrophy type 1 as a condition appearing in early childhood and gradually developing throughout life. According to Lakshminarayanan et al. [7] and other authors [6, 8], it appears during the first or second decade of life. For Beylerian et al. [9], symptoms may onset as early as 3 years old, in most cases within the first 10 years of life. In this family, the young boy's age of discovery is 6 years old. For her 11-year-old older sister, the discovery was recent during the family investigation. This could be explained by the fact that the corneal lesions are less extensive with a less marked impact on visual acuity. The father reported a decline in visual acuity that progressed from childhood. We note that in the mother, this condition probably went unnoticed with visual acuity at 10/10, although she has obvious corneal damage. For most authors, there is no difference of sex distribution. In the case of this family, both sexes are affected. We note, however, that the impact on visual acuity is less marked in mother and daughter. 
According to Munier et al., Like all corneal dystrophies in general, it is a ubiquitous disease, sparing no ethnicity, with a distribution reflecting above all, in the recessive forms, the degree of consanguinity of the populations and, for the forms dominant, a founding effect [10].

\section{Clinical aspects}

In our observation, the reason for consultation was the decline in visual acuity in the son age 6 in whom the best corrected visual acuity (BCVA) was $5 / 10$. In the rest of family, the BCVA was greater than or equal to $8 / 10$. For Beylerian et al. [9], children homozygous have more severe manifestations. In our case this hypothesis would be true for the son, but not for the daughter. Grayson et al. [11] reported that corneal opacities in granular dystrophy classic have an early onset, but vision is not impaired at this stage of development, and the patient does not feel any discomfort. Vision is usually not altered until the fourth or the fifth decade of life. This could be explained by the fact that the early lesions, mainly located in the axial part of the cornea, are small, inconspicuous, and clearly demarcated in the stroma of both eyes. Over time, the lesions progress and become larger, coalescing. They are increasing in number, and are spreading in deeper layers of stroma.

\section{Tomographic aspects}

The OCT of the anterior segment carried out in the father and the son found granular hyperreflective deposits on Bowman's membrane and on the anterior, middle, and posterior stroma. For Siebelmann et al. [13] type I granular dystrophy is characterized on OCT by the presence of hyperreflective material in the corneal stroma, epithelium and layer of Bowman. For many authors, Bowman's layer is partially disturbed [14, 15]. This aspect is consistent with that found in our patients. In OCT, the deposits are hyper-reflective, well limited, and readily polygonal in shape. The stromal surface is irregular and wavy, associated with hyperplasia and hypoplasia of the epithelium in raised areas [12]. OCT of the anterior segment is capital in the differential diagnosis of corneal dystrophies allowing a detailed analysis of the cornea by obtaining high resolution cuts. In granular corneal dystrophy type 1 , it is also useful for the choice of therapeutic techniques by specifying the depth of the lesions stromal. Finally, it is important for pre and post therapy monitoring. The recent technique, intraoperative OCT, improves and refines treatment.

\section{Genetic aspects}

In Groenouw granular corneal dystrophy type 1 , heredity is autosomal dominant with incomplete dominance and full penetrance.The R555W mutation in exon 4 of the heterozygous BIGH3 gene [16] is responsible for almost all classical Groenouw type I dystrophies, except in exceptional cases (the R124S in a single Asian family; and an R124L in a French family with a form of intermediate granular dystrophy between types I and III) [10]. In our case, the genetic study could not be performed. Histology is characterized by the presence of granular deposits staining red in the Masson's trichrome and reacting immunohistochemically with anti-keratoepithelin antibodies. Tissue analysis reveals a considerable accumulation of keratoepithelin. In electron microscopy, these extracellular deposits are made up of "rod-shaped bodies", characteristic of granular dystrophies.

\section{Therapeutic aspects}

Currently the treatment of granular corneal dystrophy type 1 is based on more or less invasive optical, medical and surgical means. No treatment of genetic cause is currently available [6]. Corrective lenses help improve visual acuity while symptomatic medical treatment aims to relieve functional signs such as pain, epithelial erosions and photophobia by the use of healing agents, wetting agents and lubricants. For this family, optical correction, wetting agents and lubricants are sufficient to treat both father and daughter. For the mother, only lubricants were required. For the son who is most affected, with a bilateral $5 / 10$ BCVA, he optical treatment was considered insufficient. The presence of anterior and deep stromal deposits objectified in OCT, directs us to a surgical option. Regarding surgical methods, various therapeutic strategies are used to improve vision by removing deposits. The treatments offer a range from less invasive therapeutic, photokeratectomy with lamellar keratoplasty, to the transfixing keratoplasty, more invasive. The choice of technique depends on the depth of the lesions in the stroma [17]. Therapeutic photokeratectomy (PKT) is the procedure of choice for the treatment of shallow corneal deposits. This technique is indicated when deposits are superficial [17, 18]. It improves visual acuity and delays the need for keratoplasty at the future, when the deposition of opacities continues. Dighiero et al. found a clear improved vision after performing PKT on 27 eyes with dystrophy corneal granular type 1 (DCG1). The preoperative mean of BCVA was 20/100, and postoperatively, it was 20/30 at one year [19]. Das et al. performed PKT in 62 eyes with DCG1 and found BCVA improved in $79 \%$ of patients. On the other hand, in this study, recurrence of DCG1 was observed in $20 \%$ of eyes after PKT. Since these recurrences tend to be earlier, PKT can sometimes be repeated.

Transfixing keratoplasty (KT) and anterior lamellar keratoplasty (KLA) have traditionally been used to treat the deep deposits of corneal stromal dystrophies, with a more recent trend towards KLA because DCG1 and others corneal dystrophies, such as granular corneal dystrophy type 2, affect especially the anterior stroma. KT is most often reserved for cases of recurrence after PKT and KLA. Seitz et al., Suggest that PKT increases visual acuity without affecting the prognosis of subsequent KT [18]. Lewis et al. analyzed 
in a retrospective study including 28 eyes of 15 patients, the recurrence of DCG1 after penetrating keratoplasty (KT), lamellar keratoplasty anterior (KLA), deep lamellar keratoplasty (KLP), and photokeratectomy therapeutic (PKT). The results found a significantly faster recurrence after PKT (median time: 2.7 years) and more delayed after KT (13.7 years). A recurrence significantly occurred at a similar intermediate interval after KLA and KLP (3.7 and 3.2 years, respectively) [20]. Recurrence-free survival is longest after KT with an associated delay in reaching MAVC. Conversely, PKT provided the fastest visual recovery with faster recurrence.

\section{Conclusion}

Granular corneal dystrophy type 1 is an inherited condition that occurs in during the first two decades and affects both sexes. It can manifest itself in severe ways in the childhood and be the cause of amblyopia, especially in homozygous subjects. Consanguinity probably increases the risk of transmission. The OCT of the anterior segment confirms the diagnosis, helps in the choice of therapeutic technique and intraoperatively, it refines the treatment. In cases of moderate impairment, optical correction and symptomatic medical treatment may be sufficient. In severe cases, PKT is the technique of choice and May, in cases of recurrence, is completed by transfixing keratoplasty, a more invasive technique that does not guarantee the absence of recurrences.

\section{REFFERENCE}

1. Groenouw A. Knotchenf ormige Hornhauttr ubungen (Noduli corneae). Arch Augenheilkd. 1890. 21:281-289.

2. Eiberg H, Moller HU, Berendt I. Assignment of granular corneal dystrophy Groenouw type I (CDGG1) to chromosome 5q. Eur J Hum Genet. 1994; 2 : 132-8.

3. Munier FL, Korvatska E, Djemai A. Keratoepithelin mutations in four 5q31-linked corneal dystrophy. Nat Genet. 1997; 15: 247-51.

4. Munier FL, Frueh BE, Othenin-Girard P, Uffer S, Cousin P, Wang MX. BIGH3 Mutation Spectrum in Corneal Dystrophies. Invest Ophthalmol Vis Sci. 2002;43:949-54.

5. Musch DC, Niziol LM, Stein JD. Prevalence of corneal dystrophie in the United States: estimates from claims data. Invest Ophtalmol Vis Sci. 2011; 52: 6959-63.

6. Bourges JL. Les dystrophies de cornée. J. Fr. Ophtalmol. 2017; 40, 7, 606-62.

7. Lakshminarayanan R, Chaurasia SS, Anandalakshmi V, Chai SM, Murugan E, Vithana EN,Beuerman RW, Mehta JS. Clinical and genetic aspects of the TGFBIassociated corneal dystrophies. Ocul Surf. 2014 Oct;12(4):234-51.
8. Han KE, Chung WS, Kim T, Kim KS, Kim TI, Kim EK. Changes of clinical manifestation ofgranular corneal deposits because of recurrent corneal erosion in granular corneal dystrophy types 1 and 2. Cornea. 2013 May;32(5):e113-20.

9. M. Beylerian, G. Ho Wang Yin, L. Hoffart. Dystrophies cornéennes héréditaires chez l'enfant. Ophtalmologie pédiatrique, Rapport SFO, 2017;224

10. Munier F, Schorderet D, Uffer S. Dystrophies héréditaires de la cornée. OEil et génétique. Rapport SFO, 2005 ; 139.

11. Grayson M. Diseases of the Cornea, 2nd ed. St. Louis: Mosby, 1983; 252-60.

12. Borderie V. Dégénérescences et dystrophies cornéennes. Surface oculaire. Rapport SFO, 2014 :367.

13. Siebelmann S, Scholz P, Sonnenschein S, Bachmann B, Matthaei M, Cursiefen C, Heindl LM. Anterior segment optical coherence tomography for the diagnosis of corneal dystrophies according to the IC3D classification. Surv Ophthalmol. 2017 S0039-6257(17)30164-9.

14. Meyer CH, Sekundo W. Evaluation of granular corneal dystrophy with optical coherent tomography. Cornea. 2004;23:270-1.

15. Munier F-L, Korvatska E, Djemai A, Le Paslier D, Zografos L, Pescia G, Schorderet DF. Keratoepithelin mutations in four 5q31-linked corneal dystrophies. Nat Genet 1997, 15 : 247- 251

16. Miura M, Mori H, Watanabe Y. Three-dimensional optical coherence tomography of granular corneal dystrophy. Cornea. 2007;26:376-4

17. Kyung Eun Han, Seung-il Choi, Tae-im Kim, Yong-Sun Maeng, R. Doyle Stulting, Yong Woo Ji, Eung KweonKim. Pathogenesis and treatments of TGFBI corneal dystrophies. Progress in Retinal and Eye Research. 2016 50, 67-88.

18. Combillet F, Touboul D, Leger F, Colin J. Dystrophie granuleuse de type Groenouw 1 traitée par kératoplastie lamellaire antérieure profonde: analyses histologique et tomographique par cohérence optique. Journal Français d'Ophtalmologie. 2012 Jan 1;35(1):50-e1.

19. Seitz B, Behrens A, Fischer M, Langenbucher A, Naumann GO. Morphometric analysis of deposits in granular and lattice corneal dystrophy: histopathologic implications for phototherapeutickeratectomy. Cornea 2004; 23:380-5.

20. Dighiero P, Ellies P, Legeais JM, Briat B, Mayer F, David T. Phototherapeutic keratectomy in the treatment of Groenouw's type I corneal dystrophy. J Fr Ophtalmol. 1999; 22:176-9.

21. Lewis DR, Price MO, Feng MT, Price FW Jr. Recurrence of Granular Corneal Dystrophy Type 1 After Phototherapeutic Keratectomy, Lamellar Keratoplasty, and Penetrating Keratoplasty in a Single Population. Cornea. 2017. 